\title{
Ventilator Associated Pneumonia: Incidence, Etiology, and Preventive Strategies
}

\author{
María Betancourt Quiles, Glorimar Santos Llanos, Ricardo Fernández González, Raúl Reyes Sosa
}

\begin{abstract}
Objective: To determine the incidence of ventilator associated pneumonia (VAP) in the intensive care unit, and to characterize most common causative pathogens and resistance pattern. To evaluate compliance to VAP prevention strategies and their documentation in order to identify areas for quality improvement.
\end{abstract}

Design: A retrospective single center study was performed in which medical records were reviewed from all patients on mechanical ventilator admitted to intensive care unit from January to December 2007. The Clinical Pulmonary Infection Score (CPIS) and problem list were used to identify VAP cases. Data on microbial isolates and antimicrobial resistance were collected as well as documentation of measures to prevent VAP.

Setting: A multidisciplinary, eight-bed Intensive Care Unit (ICU) at a metropolitan municipal hospital in Puerto Rico.
Patients and participants: A total of 60 patients that required mechanical ventilation for more than 48 hours.

Measurements and results: The overall estimated VAP rate was 37.15 . There was an extremely low compliance to head of bed elevation, daily sedation interruption and oral care. The most common pathogens identified in early and late onset VAP were Klebsiella species, Acinetobacter baumanii, and Pseudomonas aeruginosa, all being multidrug resistant pathogens.

Conclusions: The lack of compliance to VAP preventive measures as part of the routine management of patients in mechanical ventilation may explain the high VAP rate. Multidisciplinary teams are needed to establish standardized protocols as well as periodic quality improvement reviews to prevent this complication.

Key words: pneumonia, nosocomial infections, mechanical ventilation, preventive, clinical pulmonary infectious score, intensive care unit.

\section{Introduction}

Ventilator associated pneumonia (VAP) continues to be an

\footnotetext{
From San Juan City Hospital, San Juan, Puerto Rico (María Betancourt Quiles, Glorimar Santos Llanos, Ricardo Fernández González, Raúl Reyes Sosa)

Address for correspondence:

María C. Betancourt

Urb. El Señorial

333 Pío Baroja, San Juan, Puerto Rico 00926

Tel: (787) 428-8133

Fax: (787) 765-3692

Email: mcbetqui@yahoo.com
}

important cause of morbidity and mortality, especially at the setting of Intensive Care Unit (ICU). It is the leading cause of death among nosocomial infections, $(1,2)$ accounting for a hospital mortality ratio of $46 \%$. (1) It has been estimated that VAP prolongs time patients remains on the ventilator and total length of hospital stay. (3) The economical impact has been tremendous, exceeding $\$ 40,000$ for every patient.

VAP is defined as a pulmonary infection that develops in patients on mechanical ventilation after 48 hours of intubation. (5) A combination of clinical, radiographic and 
laboratory data should be considered for patients with suspected VAP. $(6,7)$ If a ventilated patient develops a new or progressive infiltrate, with fever, leukocytosis, purulent sputum and hypoxemia, the diagnosis of VAP should be considered.

Important sources of infection include healthcare devices, general ICU environment and the transfer between patients-staff and then to other patients. $(7,8,9)$ Pathogenesis has been mainly related to the access of nosocomial pathogens into the lower respiratory tract by aspiration of oropharyngeal pathogens or leakage around the endotracheal tube cuff. (7) For these reasons, all healthcare professionals should make efforts to practice effective preventive strategies to prevent this mortal complication.

The purpose of our study was to determine the incidence of VAP in the ICU, and to characterize the most common causative pathogens and resistance pattern. Since our institution has an Internal Medicine Residency and a recently developed Pulmonary fellowship, we also intended to evaluate compliance to VAP prevention strategies and their documentation in order to identify areas for quality improvement and consequently have a positive impact to decrease the rate of this complication.

\section{Methods}

Our study was approved by our Institutional Review Board. A retrospective single center study was performed at the ICU at a metropolitan municipal hospital in Puerto Rico. This is a multidisciplinary unit that combines medical, surgical, cardiac, gynecological and obstetrics patients, with a total of 8 beds. Medical records were reviewed for all patients on mechanical ventilator admitted to ICU from January to December 2007. Patients were excluded if they were intubated for less than 48 hours, or if the reason for intubation was suspected to be a hospital acquired pneumonia. The Clinical Pulmonary Infection Score (CPIS) as well as problem list documented by physicians were used to identify VAP cases. Data of microbial isolates and antimicrobial resistance were collected as well as documentation of measures to prevent VAP. Only medical patients were included in the study.

\section{Results}

Within the study period, a total of 60 patients at the ICU required mechanical ventilation for more than 48 hours. Of the above number of patients, 25 of them were diagnosed with VAP according to a CPIS greater than six, medical record problem list and clinical, laboratory, and radiographical criteria. The overall estimated VAP rate was 37.15. The most common reasons for intubation and mechanical ventilation were cerebrovascular accidents, community acquired pneumonia and cardiac complications (Table 1).

VAP cases were classified as early and late onset. The characteristics as well as compliance to VAP preventive measures are described for each group on Tables 2 and 3, respectively. An extremely low compliance to head of bed elevation, daily sedation interruption and oral care were identified. Among the 25 microbial isolates, the most common pathogens identified in both groups were Klebsiella species, Acinetobacter baumanii, and Pseudomonas aeruginosa (Table 4,5). All of these were identified as multidrug resistant pathogens.

\section{Discussion}

In this single center observational study more than one third of patients receiving mechanical ventilation developed ventilator-associated pneumonia (41\%), which is higher than the expected 10 to $25 \%$ incidence for VAP. (2) These findings may reflect the lack of compliance to VAP preventive measures as part of the routine management of patients in mechanical ventilation at this teaching institution. Most common pathogens found on sputum culture include Pseudomonas, Klebsiella, Acinetobacter, Enterobacter, Serratia and E. coli, which are expected for hospital acquired pneumonia microorganisms. (7) However, pathogen results differ from what is expected for early onset VAP. It has been established that early onset pneumonia is caused by pathogens such as Pneumococci, Staphylococci, Enterobacteriacea, and Haemophilus species (10) that may gain access to the lower respiratory tract during the process of intubation. Our early onset patients were infected with pathogens common to late onset VAP as Pseudomonas, 
Acinetobacter, Staphylococcus, and Klebsiella. This may respond to the fact that some of these patients received previous treatment with antibiotics due to another infectious process prior to the development of VAP. The risk for colonization and contamination with multidrug resistant pathogens is higher in this situation, for which their flora is similar to late onset VAP patients. These situations may also reflect the possibility that these patients had a hospital acquired pneumonia that was not identified at the time of intubation and was then diagnosed as a VAP.

The most common microbial isolates among early and late onset VAP cases were multidrug resistant pathogens. Although data about antimicrobial agents used are not shown, most of the patients were treated with three or more antibiotics. This finding may be in part the result of multiple medical staff interventions in a teaching hospital, as well as the delay in the timely availability of microbial isolates results. The use of multiple antimicrobial agents may be the contributing factor to multidrug resistance in this institution that lacks an antibiotic rotation program.

This study provided extremely valuable information regarding medical practice in our ICU. As part of a new
Pulmonary Fellowship program, quality improvement strategies are being developed and continuously evaluated. Our team pursues better documentation of preventive strategies among all healthcare professionals that have direct contact with patients, including nurses, respiratory therapists, residents, fellows and attending physicians. Endotracheal tube cuff pressure measure is being documented as well as head of bed elevation, by respiratory therapists twice per shift. Intensive care unit and ventilator order sets are also being created to ensure that every measure is being taken to prevent this dreadful complication. These orders include head of bed elevation, stress ulcer and thromboembolism prophylaxis and daily interruption of sedative medications.

Limitations of this study include a single center scenario as well as the retrospective assessment of VAP cases. Although data used to evaluate and identify every case involved clinical, laboratory, and radiography criteria, as well as the CPIS, these do not guarantee the real facts as when data is being collected in a prospective study. Thus, we intend to repeat this study after all quality improvement strategies are established and with a prospective evaluation. We will compare results from both studies to determine the impact of these in the VAP rate of our institution. 
Table 1. Reason for Mechanical Ventilation Among Early and Late Onset VAP

\begin{tabular}{|l|c|c|}
\hline \multicolumn{1}{|c|}{ Diagnosis } & Early onset & Late onset \\
\hline Cerebrovascular accident & 2 & 2 \\
\hline Community acquired pneumonia & 0 & 4 \\
\hline Cardiac (myocardial infarction, unstable angina, & 2 & 1 \\
uncompensated congestive heart failure) & & 2 \\
\hline CNS* toxoplasmosis & 0 & 2 \\
\hline Sepsis (soft tissue infections) & 1 & 0 \\
\hline Upper gastrointestinal bleeding & 1 & 1 \\
\hline Bacterial endocarditis & 1 & 1 \\
\hline Delirium tremens & 0 & 0 \\
\hline Diabetic ketoacidosis & 0 & 1 \\
\hline Adrenal crisis & 0 & 2 \\
\hline Uncompensated COPD* & 0 & 2 \\
\hline Drug overdose, rhabdomyolysis & & 1 \\
\hline Acute renal failure & & \\
\hline
\end{tabular}

${ }^{*} \mathrm{CNS}=$ central nervous system, $\mathrm{COPD}=$ chronic obstructive pulmonary disease. 
Table 2. Characteristics of Early Onset Pneumonia Patients $(n=8)$

\begin{tabular}{|l|c|}
\hline \multicolumn{1}{|c|}{ Characteristic } & Result \\
\hline Age, mean (range) & $50(30-71)$ \\
\hline Women, no. (\%) & $3(37.5)$ \\
\hline Men, no. (\%) & $5(62.5)$ \\
\hline Days in MV, mean (range) & $11(5-15)$ \\
\hline Preventive measures documentation, no. of patients (\%) & $8(100)^{*}$ \\
- NGT & $0(0)$ \\
- Head of bed elevation & $8(100)^{* *}$ \\
\hline$\quad$ DVT prophylaxis in patients without contraindications & $7(100)$ \\
- Oral care & $7(87.5)$ \\
\hline
\end{tabular}

*NGT documented as placed but not part of physicians' orders

**Exact measure not documented 
Table 3. Characteristics of Late Onset Pneumonia Patients $(n=17)$

\begin{tabular}{|c|c|}
\hline Characteristic & Result \\
\hline Age, mean (range) & $57(37-81)$ \\
\hline Women, no. (\%) & $9(52.9)$ \\
\hline Men, no. (\%) & $8(47.0)$ \\
\hline Days in MV, mean (range) & $19.2(6-40)$ \\
\hline Preventive measures documentation, no. of patients (\%) & \\
\hline - NGT & $17(100)^{*}$ \\
\hline - Head of bed elevation & $0(0)$ \\
\hline - ETT cuff pressure measurement & $17(100)^{* *}$ \\
\hline - DVT prophylaxis in patients without contraindications $(\mathrm{n}=11)$ & $10(90.9)$ \\
\hline - Compressive stocking ordered for patients with contraindications for & \\
\hline prophylaxis $(\mathrm{n}=6)$ & $4(66.7)$ \\
\hline - Stress ulcer prophylaxis & $17(100)$ \\
\hline - Oral care & $0(0)$ \\
\hline - Daily sedation interruption & $8(47)$ \\
\hline
\end{tabular}

*NGT documented as placed but was part of physicians' orders in $5(29 \%)$ of cases

**Exact measure not documented 
Table 4. Most Common Pathogens on Sputum Cultures of Early Onset VAP Cases

\begin{tabular}{|l|c|}
\hline \multicolumn{1}{|c|}{ Pathogen } & Number (\%) \\
\hline Klebsiella pneumoniae & $3(37.5)$ \\
\hline Klebsiella ozaenae & $1(12.5)$ \\
\hline Acinetobacter baumanii & $4(50)$ \\
\hline Staphylococcus aureus & $1(12.5)$ \\
\hline
\end{tabular}

Table 5. Most Common Pathogens on Sputum Cultures of Late Onset VAP Cases

\begin{tabular}{|l|c|}
\hline \multicolumn{1}{|c|}{ Pathogen } & Number (\%) \\
\hline Klebsiella pneumoniae & $6(35.3)$ \\
\hline Pseudomonas aeruginosa & $4(23.5)$ \\
\hline Acinetobacter baumanii & $7(41.1)$ \\
\hline Enterobacter cloacae & $2(11.8)$ \\
\hline Escherichia coli & $2(11.8)$ \\
\hline Serratia marcescens & $1(5.9)$ \\
\hline
\end{tabular}




\section{References}

1. Ibrahim EH, Tracy L, Hill C, Fraser VJ, Kollef MH. The occurrence of ventilatorassociated pneumonia in a community hospital: risk factors and clinical outcomes. Chest 2001;120:555-61.

2. Craven DE. Preventing ventilator-associated pneumonia in adults: sowing seeds of change. Chest 2006;130:251-60.

3. Rello J, Ollendorf DA, Oster G, Vera-Llonch M, Bellm L, Redman R, et al. Epidemiology and outcomes of ventilator-associated pneumonia in a large US database. Chest 2002;22:2115-21.

4. Tablan OC, Anderson LJ, Besser R, Bridges C, Hajjeh R; CDC, et al. Guidelines for preventing health-care--associated pneumonia, 2003: recommendations of
$\mathrm{CDC}$ and the Healthcare Infection Control Practices Advisory Committee.. MMWR Recomm Rep 2004;53:1-36.

5. Kollef MH. The prevention of ventilator associated pneumonia. $\mathrm{N}$ Engl $\mathrm{J}$ Med 1999;340:627-34.

6. Center for Disease Control and Prevention. The National Healthcare Safety Network Manual. Patient Safety Component Protocol [Online]. 2008 Jan; Available from: URL:http://www.cdc.gov/ncidod/dhqp/pdf/ nhsn/NHSN Manual PatientSafetyProtocol CURRENT.pdf.

7. Guidelines for the management of adults with hospital-acquired, ventilator-associated, and healthcare-associated pneumonia. Am J Respir Crit Care Med 2005;171:388-416.
8. Chastre J, Fagon JY. Ventilator-associated pneumonia. Am J Respir Crit Care Med 2002;165:867-903.

9. Pittet D, Hugonnet S, Harbarth S, Mourouga P, Sauvan V, Touveneau S, et al. Effectiveness of a hospital-wide programme to improve compliance with hand hygiene. Infection Control Programme. Lancet 2000;356:130712.

10.Giantsou E, Liratzopoulos N, Efraimidou E, Panopoulou M, Alepopoulou E, KartaliKtenidou S, et al. Both early-onset and lateonset ventilator-associated pneumonia are caused mainly by potentially multiresistant bacteria. Intensive Care Med 2005;31:148894. 